\title{
Recurrent Childhood Hodgkin Lymphoma
}

National Cancer Institute

\section{Source}

National Cancer Institute. Recurrent Childhood Hodgkin Lymphoma. NCI Thesaurus.

Code C8059.

The reemergence of Hodgkin lymphoma after a period of remission during childhood. 